\title{
Intergrated Approach to Health Promotion: The South African Schools' Role
}

\section{Dr Siphokazi Kwatubana}

sipho.kwatubana@nwu.ac.za

Jabulani Kheswa

jkheswa@ufh.ac.za

\section{Doi:10.5901/mjss.2014.v5n20p1713}

\begin{abstract}
This research sought to examine the schools' role in integrated health promotion. The key focus was on the understanding of the integrated policies and the implications of practical implementation of such policies in schools. This research was explorative in nature and involved a stratified sample of 16 participants from one of the municipalities under Sedibeng District Municipality. The findings revealed that the schools' ineffectiveness in their role is a barrier to efficient health services by health teams. There is lack of coordination and collaboration of health services due to lack of training and accountability.
\end{abstract}

Keywords: health promotion at schools, integrated approach to health promotion, school readiness, health policies in schools, Integrated School Health Policy

\section{Introduction}

Social, emotional and physical functioning are critical factors in learners' academic achievement, therefore, it is important that education be conceded in environments that are healthy. According to the Department of Basic Education (2013 p. 64) and Education For All (EFA) (Little, 2011 p.19), in order for schools to be efficient and effective in terms of health promotion, the prerequisite is to prioritise the creation of safe, healthy, inclusive and equitably resourced educational environments that are conducive to excellence in learning. Benefits of such healthy environments are well documented in the literature. According to Sinnott (2005), a focus on health promotion improve knowledge, competencies and health status, thereby leading to enhanced learners' learning outcomes, through shaping of the attitudes of learners towards effective teaching and learning behaviour (Berry, 2002). When health promotion is neglected children are placed at a greater risk for academic failure which can trigger a ripple effect on the performance and effectiveness of the whole school.

Health promotion in South African schools has since 1994 been guided by policies that are geared towards providing healthier, enabling school environments. The policy background is important for the understanding of the range of interventions targeted for health promotion. The National School Nutrition Programme (South Africa, 1994) which allows for provision of nutritious meals to learners in primary schools under Quintiles 1, 2 and 3, was later expanded to secondary schools. The effective implementation of the NSNP is believed to contribute to general health development of learners and their academic performance by promoting punctuality, regular school attendance, concentration and alleviating short term hunger. Furthermore, the National Policy on HIVIAIDS (1996) focuses on providing adequate information and education on issues of sexuality, thereby allowing safer settings in terms of physical protection from the HIV. The basic premise towards the development of inclusive learning communities is specified in the Education White Paper 6 (Department of Education, 1996). To systematize the development of such inclusive school communities the National Strategy on Screening, Identification and Support (SIAS) (South Africa, 2008) was established to directly respond to the needs of the most vulnerable learners and those at risk, by enabling schools to provide appropriate interventions and support through the District Based Support Teams (DBST) and School Based Support Teams (SBST). Through Curriculum and Assessment Policy Statement (South Africa, 2012) Life Skills and Life Orientation supply learners with important and useful information about health issues.

However, Hawkins, Catalano, Kosterman, Abbot and Hill (1999) argue that policies such as those discussed in the forgoing paragraph are single interventions which provide a narrow approach and targeting a single risk factor. Such policies may not adequately address the different risk processes that may lead to the same problem behavior as they 
provide services that are disjointed. The key endeavour of the integrated health approach is to keep the unique strategies of each policy intervention such as, HIV, nutrition, inclusion, health and education and merge those that overlap, conveying a comprehensive set of approaches which target multiple health factors simultaneously. The extent to which these unique strategies are coordinated to bring about coherence in terms of objectives and operations, stirring away from fragmentation will determine the extent of integration. Proponents of the integrated approach to health promotion argue that both preventative and curative interventions are provided in such an approach. Although few would question the appeal of integrated health promotion with its implications of care and support for all, the procedure and practicality of the implementation remains a subject of debate. All policies are only effective when implemented and schools are thus, at the forefront of these complexities and tensions.

Few studies have been conducted on the school's role in the integrated approach to health promotion as it is relatively a new concept. Studies that investigated barriers to school health services and health promotion include those of Mohlabi, Van Aswegen and Mokoena (2010) and Mukoma and Flisher (2004). The main objective of this research is to investigate the role of schools in the implementation of integrated health policies following an integrated approach to health promotion.

\section{Integrated Approach to Health Promotion and the Role of Schools}

To live up to the commitment of providing coordinated care for all learners, rather than separate policies for separate interventions, the Department of Education came up with a five year plan (2012-2016) an integrated strategy (Department of Basic Education, 2010) focusing on addressing the prevention, diagnosis and treatment of HIV, STIS and TB. The response to HIVIAIDS, TB and STIs had to be further strengthened as the HIV prevalence was indicated as still high at 17.3 percent in 2011 (UNAIDS, 2012) leading to the increasing mortality rate with its immense emotional impact on learners at schools, compelling schools to provide nurturing, caring environments that are safe and conducive to learning. The latest addition to such policies is that of the Integrated School Health Policy (ISHP) (South Africa, 2012) which also fosters a supportive culture that reflects commitment to the promotion of wellbeing of all learners, fostering a progress towards optimal health. Subsequently, the exposure of learners to a wider range of integrated health interventions is maximised. These policies also advocate for adoption of collaborative and consultative approaches to the delivery of health services at school level. It is the understanding of these approaches that will determine the extent of integration of health policies at schools.

Domitrovich, Bradshaw, Greenberg, Embry, Poduska and lalongo (2009 p. 74) are of the opinion that the integrated approach is cost effective in that resources are shared, more intensive and has a potential to improve intervention impact in an efficient manner. The goal of integration in school health services is to create a more efficacious preventive and promotive intervention that aims at impacting on a range of risk and protective factors to support a healthy environment for all by facilitating access to health services. A key role of schools implementing such policies is to have strategies in place to strengthen the schools' capacity to promote convergence in integrated policies and operations for health promotion for the whole school community.

To garner a sustained response to such an integrated and comprehensive strategy would mean that first; the intervention be streamlined so that it becomes feasible for educators and school personnel to use in schools. The ISHP (South Africa, 2012) and the Integrated Strategy on HIV, STIs and TB 2012 - 2016 (2012) indicate that it is the responsibility of the School-Based Support Team (SBST) guided by the principal to implement these integrated policies at school level. The table below illustrates the composition and roles of the SBST members.

Table 2.1 Composition of the SBST in White Paper 6 and ISHP

\begin{tabular}{|l|l|}
\hline \multicolumn{2}{|c|}{ SBST according to White Paper 6} \\
\hline Coordinator & Any member of the SBST can coordinate \\
\hline Educator (not a permanent member) & Referral teacher \\
\hline Parent (not a permanent member) & Parent of the child with learning barriers \\
\hline A skilled educator & Educators with knowledge and skills in learning support, Life Skills/guidance and counselling \\
\hline Educator & Any educator with interest in supporting learners \\
\hline Educator & Chairperson of the TAT \\
\hline Principal & Ex officio member \\
\hline
\end{tabular}

The table above includes the co-members of the SBST as indicated in White Paper 6 (1996). The ISHP also mandates 
the inclusion of a member of the SGB, representative of NGOs or CBOs and learners. These people according to White Paper 6 are additional members included to garner community-based expertise. It remains to be seen if the SBST will not end up bloated and malfunctioning because of too many people who might not even have clear roles. However, the inclusion of the School Health Team and a Life Skils/Life Orientation educator changes the functioning of the SBST from that of being responsive by just addressing problems through curative programmes to that of being salutogenic (Engelbrecht, Green, Naicker \& Engelbrecht, 1999 p. 61) and developmental. The focus also shifts from only learners identified as having problems to caring for all learners (Adelman \& Taylor, 2003). These strategies are complex for educators and principals who are used to a certain degree to focus on a single intervention and to a greater extent on curriculum. Change is thus, complex, according to Sands, Kozleski and French (2000) health promotion for all learners means a shift from embedded assumptions that encourage maintenance of status quo to one that promotes the implementation of a combined intervention, lack of understanding of roles therefore could lead to resistance to such change and retard the progress made.

Second, Domitrovich, et. al. (2009 p. 78) argue that schools need to understand that integration is not simply adding two interventions; rather, a blending of overlapping components of unique elements to maximize the mechanisms of change that underlie each intervention, it is thus much more complex. For instance, the DBE Integrated Strategy on HIV, STIS and TB 2012-2016 (2010) is to integrate and align HIV and AIDS and Life Skills Education Programme with health-related programmes. The ISHP (South Africa, 2012) integrates health education, health promotion and learner assessment and screening and immunisation. This means that the Life Skills Programme/ Life Orientation has increasingly shifted to incorporate activities beyond curriculum concerns, including those that are care and supportrelated. In recognising the complexity of such tasks, it is not surprising that integrated policies recommend the collaboration of health teams and the SBST be strengthened to meet the demands of advocacy, communication and social mobilisation, to ensure continuity of care for learners. It can be difficult for the SBST to perform such a task as according to Stofile and Green (2007 p.56), cultural ethos of collaboration have not yet been conceptualised at schools due to a history of working in silos.

Third, a system of training and support that fosters high-quality implementation needs to be created. A study conducted in the Western Cape by Waggie, Laattoe and Fillies (2013) found that there was a shortage of trained educators who can initiate or assist in the implementation of ISHP, thus, the understanding of the concept of health promotion was lacking. There is also a lack of clarity on the strategies to support principals and educators in implementing policy assignments indicated in the ISHP (South Africa, 2012). It is important that all stakeholders such as educators, school managers, learners, parent community and education officials be fully informed about changes and new developments so as to understand and commit to their own role in the collaborative process.

Fourth, a system to monitor the implementation is needed as although the ISHP (South Africa, 2012) on one hand states clearly who monitors and what is to be monitored for an example the coverage and quality of services, the impact of the service on learners' health and the sustainability of health services in schools, the Department of Basic Education on the other hand intends to make use of the Education Management Information System (EMIS), Learner Unit Record Information Tracking System (LURITS) and the Screening, Identification, Assessment and Support (SIAS) tracking devices to monitor and evaluate the integrated strategies. The school has to develop its own monitoring system to evaluate the effectiveness of its involvement.

It is important to understand the role of school nurses who because of the fact that they work in groups of 2-4 health practitioners depending on the capacity of the health district, are referred to as health teams.

\section{The Role of School Health Teams}

According to the ISHP (South Africa, 2012) schools are allocated health teams which visit schools and provide health services to all learners in Quintiles 1, 2 and 3 schools, thus, focusing on children from poor communities with less or no access to health services. An important finding regarding the frequency of visits in schools in a study conducted in the Western Cape (Waggie et al, 2013) was that there were too few visits by health teams. This is not surprising as according to the ISHP (South Africa, 2012) health professionals are to assess learners once during each of the four educational phases of schooling except in cases where learners are repeating grades. A finding in Mohlabi et al (2010 p. 253) study confirms the problem of few visits indicating that nurses in the Mpumalanga and Gauteng provinces visit once a year or once in two to three years.

Three roles of school nurses indicated in the ISHP (South Africa, 2012) include immunisation and health screening, health promotion and health education, it is thus important for school nurses to be physically present in schools to carry such responsibilities appropriately (American Academy of Pediatrics, 2008 p. 1052). These focus areas are important for 
health care that is seamless and easy to navigate. Health screening provides an opportunity for early identification of barriers to learning and provision of appropriate intervention to learners, it has a potential to decrease negative impact of ill health on education. However, there should be close communication between the health teams and the SBST for regular updates that will assist in the development of individualised plans to support learners with learning barriers as it is also a health professional who can assess such a learner.

In health education the role of school nurses according to the American Academy of Pediatrics (2008 p. 1052), is to provide health information to individuals and groups of learners focusing on co-curriculum activities as indicated in the ISHP (South Africa, 2012 p.12). This indicates a relationship between health and learning. The school nurse also provides for the physical and emotional safety of the school community by monitoring immunizations, ensuring appropriate exclusion for infectious illnesses, and reporting communicable diseases as required by law, thereby, promoting a healthy school environment.

\section{Methodology}

A qualitative, explorative and descriptive method of research was used in this study. The main objective for the use of exploratory design was to provide insights and understanding regarding the role of schools in integrated health promotion.

\subsection{Sampling}

The population was limited to a sample purposefully selected from schools in Gauteng province. Getting schools who were part of the integrated health service was easy as that information was readily available in the school districts, but after I started with one primary school I realised that I needed to interview a nurse. No one in the school had any information about nurses rendering these services at their schools. I then decided to get to a nearby clinic after explaining why I required information from a school nurse she referred me to her friend. The friend was a qualified nurse who was retired but because of shortage of nurses was brought back into the system. This was a snowball kind of sampling as after interviewing the nurse she also referred me to a health promoter who was working with her in all primary schools allocated to them and later to other two health practitioners who were rendering services to all high schools in their area. After interviewing nurses and health professionals I decided to choose four schools (two primary and two high schools) under these teams' jurisdiction.

These two health teams ( 2 nurses and 2 health promoters per team) were responsible for 118 quintiles 1 and 2 primary and secondary schools in one of the three municipalities in the Sedibeng District Municipality. Initially these four health practitioners formed one team but when they realised the number of schools they had to cover they decided to split into two health teams, one responsible for all primary schools (62) and the other for all high schools (56). The sample composed of coordinators of SBSTs $(n=4)$, educators $(n=4)$, principals $(n=4)$ and two health teams $(n=4)$. The selection of different role players educators, principals, parents and nurses broadened the data collected.

\subsection{Data collection}

All data was collected from public schools chosen from the 118 schools in one of the municipalities under Emfuleni district municipality. A narrative approach was appropriate for nurses who were asked to talk about their role and that of schools under their jurisdiction. Semi-structured interview questions followed for clarity on the information given. Each individual interview lasted for an hour, afterwards the data had to be verified and follow up questions asked to clarify some issues.

Semi-structured individual interviews were conducted with the participating educators and principals. Some of the questions asked were based on the challenges that were highlighted by health practitioners such as: (a) problems with booking of classes for health services (b) their role in the implementation of the ISHP (c) their knowledge of the ISHP (d) how they think the ISHP helps the schools in their efforts to promote health.

The recorded data was listened to and transcribed by both researchers, the data was also analysed and interpreted separately by researchers, a member check for biases was done by critiquing each other's field notes, analysis of different themes that each researcher came up with. An inductive approach was used to allow the findings to emerge from themes innate in the raw data. After a lengthy reading and grouping of themes we were left with the themes that are analysed below. 


\title{
5. Results
}

\subsection{Administration of health services was poor}

There were no clear administrative procedures followed at the participating schools. Health teams had to make appointments to conduct screening, assessments and immunisation before they come to schools. These appointments were not a guarantee that the services would be provided on the set dates.

\begin{abstract}
"the nurses make appointments with the me or the deputy if she is not there"(P1); "the teachers of the classes visited have to make sure that nurses find learners in their classes"(P2); "there are delays, sometimes when the educator we make an appointment with is absent, we can't continue, we have to go back (Nurse 1)"; "when the teacher for the class we visit was not made aware of the visit it's a problem, children have to start with the cleaning of the classroom, sometimes we just decide to do this ourselves to save time"(Nurse 2); ":one is never sure whether the school will be ready for us on the appointed day or not" (Nurse 3); "it is inconvenience, we have a time table it is difficult for use to meet our targets, it is frustrating" (Nurse 4).
\end{abstract}

Nurses had to sign the log book every day when they leave and indicate what the purpose of the visit was. The log book was used as proof by principals that nurses were providing such health services.

"each time they come they sign and indicate the purpose of their visit in the log book"(P3); "it helps me to check what learners have been helped with"(P2).

In all participating schools there were no extra venues for screening and assessment of learners. Principals and educators were also concerned about lack of venues in that privacy was compromised especially where health teams were accommodated in the staffroom where teachers move in and out in between their classes. Booking classes for health services in advance was therefore not a guarantee that health teams would find venues and learners ready for them.

"nurses work in the class of the educator whose class is visited" (E1); "sometimes we accommodate them in the staffroom, this is not nice as there is no privacy"(E2); "nurses do not like to work in our school hall but there is nothing else we can do"(E3); "I wish there was a mobile class, nurses would be stationed there permanently"(P4); "it is difficult to work with learners in the staff because of noise" (N3); "we do not make much progress in the staff room we are disturbed and learners also" (N1)

\subsection{Lack of understanding of roles by school personnel}

The school managers' role was indicated as only administrative by participating principals, they didn't provide much support to nurses. SBST coordinators on the other hand were neither aware of the ISHP nor of their responsibility stated in the policy.

\begin{abstract}
"make the educator whose learners are visited aware of a visit"(P4); "it is the responsibility of the teacher to make sure that the class is clean and learners are ready"(P2); "my role is just to provide them with a class" $(P 1)$; " they communicate with parents regarding referrals not with us"(P4); "we are responsible for the White paper on inclusion, that's all (S1); "we do not have that policy" (S2); "our responsibility is to refer learners with barriers to the district" (S3); "nurses are doing their thing, we are doing ours" (S4).
\end{abstract}

\subsection{Health service delivery is not integrated in schools}

There were no educators involved in the process of the implementation of the ISHP in the participating schools. The nurses were communicating with the principal in all schools, although the principal is an ex officio member of the SBST the coordinators were supposed to be working hand in hand with the school health teams. This lack of coordination between the health teams and the SBST is contrary to the stipulation of the ISHP.

"we have never met with nurses"(S3); "we do not know what they do, I think it doesn't concern us"(S4); "we have our meetings without nurses, we never involve them"(S1); "we send sick learners and those with learning barriers to them"(E4); "we still refer our learners to the DBST not nurses, it is the DBST that can make such a decision"(S2); "we do not have a nurse in our SBST, these nurses are busy when they come they are with learners in a class for days"(S2); 


\title{
"nurses only meet with parents of children they are referring for further observation" (E2)
}

There is a lack of support by SBSTs with parents, for instance, when nurses referred learners for further observation to specialist health professional. Nurses only communicated with parents. Some of these parents did not bother to meet with the nurses as they did not regard this activity as part of school.

\begin{abstract}
"some parents do not come when we call them"(Nurse 2); "if parents do not come there is nothing we can do" (Nurse 3); "we do not talk about nurses coming to school in our parents meetings"(P1); "it is not our responsibility to talk about nurses with parents, there is nothing about that in our agenda"(P4); "it is their responsibility, we can assist may be with making the parent aware of the importance of taking the child for observation" (S1); "I know of parents who refused take their children to the clinic after being referred by nurses" (E3); "I think parents should be informed about this in a parents meeting" (E4)
\end{abstract}

In all participating schools personnel were not aware of the integrated policy, they were still implementing HIV, health and policies in inclusion in isolation, they were working separately in their small groups without integration of the policies.

"we are still using the White Paper"(S1) "that policy (ISHP) is not implemented by us we have nothing to do with it"(S2); "health policies are not part of what we do as SBST"(S3); "we have a health committee that focuses on those things, we are not part of it"(S4); "we have not been trained on the implementation of that policy, that is why we use White Paper"(S1); "we have our health policy at school we meet as members of the committee to implement it"(P3).

\subsection{There is synchronization in Health Education}

There seems to be harmonization regarding health education in the participating schools. The health team commenced each session with health education based on the purpose of their visit on that day. The topics mostly discussed included those that are indicated in the policy. This therefore means that health education is supplemented and extended beyond the classroom environment.

\begin{abstract}
"we first talk about health issues related to the purpose of our visit"(N4); "it is important for learners to be given relevant health information"(N1); "it is the procedure we have to follow we don't just immunise or provide health screen to learners "(N2); "there is a difference, we want them to understand that the information we give them is for them to do and not just to know".(N3).
\end{abstract}

\section{Discussion}

The study's finding corroborated by Waggie et al (2013) is that educators are not yet synthesised into the "health promoting school" model as they do not perceive the health teams as resources that can assist in solving most of the health problems encountered by learners. This means that the tendency to treat health programmes in isolation in such a way that they become tiny and insignificant still continues at schools. SBST members are not involved in any of the health activities as indicated in the ISHP, educators and principals were not aware of such a responsibility. The implication is that the ISHP has not yet been communicated to schools and no training has been conducted, therefore the collaboration required cannot materialise. Besides, according to Lee, Tang, Lee and To (2003) school health in terms of curriculum, have little understanding of how community partnership might work, and have little pre-service and in-service training

There are administrative aspects that need to be systematically addressed and prevented at schools to assist health teams to deliver their service efficiently. These aspects include unavailability of classrooms in some schools, lack of dedicated school managers to ensure that the provision of health service in their schools is smooth running. The results of this research suggest that administrative actions are critical in limiting challenges and delays in the implementation of integrated policies. The lack of readily available venues to aid the efficiency of health services is an issue to be considered both at school and at a national level. In some instances venues are available but because of lack of accountability also reflected in the findings of Agron et al (2010) and McKenna (2010) highlight its consequence on the quality and effectiveness of health services rendered.

Topics in Life Orientation and Life skills are supplemented during visits by health teams at schools. Besides the opportunity to take such health issues out of the classroom into the real world of the learner, the provision of additional co-curriculum activities by nurses render a strategy for reinforcement of health education delivered in the classroom. It is unfortunate that only schools in Quintiles 1 and 2 benefit from such an important endeavor. The effective use of 
supplemented health education could address problems associated with ineffective instructional methods and disinterest

by some educators regarding some topics in this learning area.

\section{References}

Adelman, H.S. \& Taylor, L. 2003. On sustainability of project innovations as systemic change. Journal of Educational and Psychological Consultation, 14:1-25.

Agron, P., Berends, V., Ellis, K. \& Gonzalez, M. 2010. School wellness policies: perceptions, barriers, and needs among school leaders and wellness advocates. Journal of School Health, 80(11):527-35

American Academy of Pediatrics, 2008. Role of the school nurse in providing school health services. Journal of the American Academy of Pediatrics, 121(5): 1052-1056.

Berry, A. 2002. Healthy school environment and enhanced educational performance: The case of Charles Young elementary school, Carpet and Rug Institute.

Department of Basic Education, 2010. HIVIAIDS, TB and STIs integrated strategy (2012-2016). Pretoria: Department of Basic Education.

Department of Education 1996. The National Policy on HIVIAIDS, Act 27 of 1996. Pretoria: Government Printer.

Department of Education, 1996. Education White Paper 6, special needs education. Pretoria: Department of Education.

Domitrovich, C.E., Bradshaw, C.P., Greenberg, M.T., Embry, D., Poduska, JM. \& lalongo, NS. 2009. Integrated models of school-based prevention: logic and theory. Psychology in the schools, 47(1):71-88.

Edwards-Miller, J. \& M. Taylor, 1998. Making a difference to school children's health: An Evaluation of School Health Services in KwaZulu-Natal, South Africa

Engelbrecht, P., Green, L., Naicker, S. \& Engelbrecht, L. 1999. Inclusive education in action in South Africa. Pretoria: Van Schaik Publishers.

Hawkins, J. D., Catalano, R., Kosterman, R., Abbot, R. D., \& Hill, K. G. 1999. Preventing adolescent health-risk be-havior by strengthening protection during childhood. Archives of Pediatrics and Adolescent Medicine, 153, 226 . 234.

Jourdan, D. 2011. Health education in schools: the challenge of teacher training. Saint-Denis cedex: Jean-Marc Piton

Lee, Tang, Lee \& To 2003. A comprehensive "Healthy Schools Programme" to promote school health: the Hong Kong experience in joining the efforts of health and education sectors . Journal of Epidemic and Community Health, 2003;57:174-177

Little, A.W. 2011. A review of major global initiatives related to Education for All (EFA) and the education specific Millenium Development Goals (MDGs). Paris: EFA global Partnerships team, UNESCO.

McKenna ML. 2010. Policy options to support healthy eating in schools. Canadian Journal of Public Health, 101(8, Suppl 2):S14-7

Mohlabi, DR., Van Aswegen, EJ. \& Mokoena, JD. 2010. Barriers to successful implementation of school health services in the Mpumalanga and Gauteng Provinces. South African Family Practice, 52(3): 249-254.

Mukoma, W. \& Flisher, AJ. 2004. Evaluations of health promoting schools: a review of nine studies. Health Promotion International, 19(3): 357-368.

Probart C, McDonnell E, Weirich JE, Schilling L. \& Fekete V. 2008. Statewide assessment of local wellness policies in Pennsylvania public school districts. Journal of American Dietetic Association, 108(9):1497-502

Reddy P, James S. \& McCauley, A. 2005. Programming for HIV prevention in South African schools: a report on programme implementation. Horizons Final Report. Washington, DC: Population Council; 2005.

Sands, D.J., Kozleski, E.B. \& French, N. 2000. Inclusive education for the 21st century: A new introduction to special education. Belmont, CA: Wadsworth

South Africa 1994. Department of Education, the National School Nutrition Programme. Pretoria: Government Printer.

South Africa. 2008. Department of Education, the National Strategy on Screening, Identification and Support (SIAS) (2008). Pretoria: Government Printer.

South Africa. 2012. Department of Basic Education. Curriculum and Assessment Policy Statement (CAPS) Pretoria: Government Printer.

South Africa 2012. Integrated School Health Policy. Pretoria: Government Printer.

Stofile, SY \& Green, L. 2007. Inclusive education in South Africa (In responding to challenges of inclusive education in Southern Africa. P. Engelbrecht \& L. Green (eds) Pretoria: Van Schaik Publishers).

UNAIDS, 2012. World AIDS day report web: http://www.unaids.org/en/resources/campaigns/20121120_globalreport2012/results. Date of access 18/06/2014

Waggie, F., Laattoe, N. \& Fillies, GC. 2013. Moving from conversation to commitment: optimising school-based health promotion in the Western Cape, South Africa. African Journal of Health Professions Education, 5(1).

Who, 2008. Integrated health services: what and why? Policy Brief 1. Geneva, World Health Organization Geneva, World Health Organization 